\section{The Ethics of Interstitial} and Cesarean Scar Ectopic Pregnancies: Four Case Studies and a Review of the Literature
The Linacre Quarterly 2018, Vol. 85(3) 252-269

(c) Catholic Medical Association 2018 Article reuse guidelines: sagepub.com/journals-permissions DOI: I0.1 I 77/00243639|8788858 journals.sagepub.com/home/lqr

\title{
Cara Buskmiller, MD
}

\begin{abstract}
Catholic bioethicists have extensively addressed extrauterine tubal pregnancies, which represent the great majority of ectopic pregnancies. However, additional management options have been developed for the other 7-10 percent of ectopic pregnancies. Using two cases of interstitial pregnancy and two cases of cesarean scar pregnancy (CSP) seen at a Catholic tertiary care center, this article discusses options including expectant management, systemic methotrexate, intragestational methotrexate, intragestational potassium chloride, uterine artery embolization, dilation and curettage (D\&C), vasopressin use, cornuostomy, cornual wedge resection, CSP evacuation, CSP scar excision, CSP salvage, and hysterectomy. Cornual wedge resection, vasopressin use, and CSP scar excision are morally acceptable; less clearly licit are aspiration of gestational sac contents, cornuostomy, gestational excision for CSPs, and methotrexate. Certainly illicit are any techniques leading to direct abortion such as D\&Cs on live embryos or fetuses, double-balloon catheter placement, and use of potassium chloride.
\end{abstract}

Summary: An ectopic pregnancy is any pregnancy outside the uterus. These are dangerous because the pregnancy can burst out of its abnormal location and cause life-threatening internal bleeding. Most are in the part of the fallopian tube outside the uterus, but there are other types, including interstitial pregnancies (located in the part of the tube tunneling through the uterine wall) and cesarean scar pregnancies (buried in the uterine scar where the cut for a $\mathrm{C}$-section was made). This article lists the ways that physicians prevent women from dying from interstitial and cesarean scar pregnancies and proposes which treatments are morally acceptable.

\section{Keywords}

Bioethics, Cesarean scar pregnancy, Ectopic pregnancy, Indirect abortion, Interstitial pregnancy, Methotrexate, Vasopressin

Catholic bioethicists have extensively addressed extrauterine tubal pregnancies, which represent the great majority of ectopic pregnancies. A consensus accepts salpingectomy, a few defend salpingostomy, and most recommend against the use of methotrexate, although many Catholic institutions and physicians still offer the latter two options. See, for a representative and recent sample, the work of Hager (2016), DeGoede (2014), Foster, Dennis, and Smith (2011), Kaczor (2009), and Guevin (2007).

However, 7-10 percent of ectopic pregnancies occur outside of the extrauterine fallopian tube and are more dangerous secondary to their locations and the difficulty of diagnosing them (Shen et al. 2014). These pregnancies require different management than extrauterine tubal ectopic pregnancies. The wide variety of therapies recommended in medical literature creates a complex decision for the physician who wants to abide by Church teaching. Yet, with attention to the details of the pregnancies,

Department of Obstetrics, Gynecology, and Women's Health, St. Louis University, St. Louis, MO, USA

\section{Corresponding Author:}

Cara Buskmiller, MD, Department of Obstetrics, Gynecology, and Women's Health, St. Louis University, 6420 Clayton Road, St. Louis, MO 63117, USA.

Email: cbuskmiller@gmail.com 
treatments, and principles of Catholic bioethics, a physician faced with an unusual ectopic pregnancy can offer management with moral certitude.

This article presents two cases of interstitial pregnancy (IP) and two cases of cesarean scar pregnancy (CSP), which are two relatively common types of ectopic pregnancies that have many proposed treatments. This article assists the Catholic obstetrician/ gynecologist and other involved personnel in making ethical treatment decisions. Several general principles require brief mention before discussion of the cases.

Firstly, normal implantation and growth to term requires that the embryonic trophoblast invade endometrial tissue backed by thick myometrium. These tissues are located only inside the endometrial cavity. While there are rare cases of viable infants delivering after ovarian, hepatic, and abdominal pregnancies, most ectopic pregnancies cannot result in a live-born, viable infant.

Secondly, the placenta is part of the fetus. ${ }^{1}$ Historically, trophectoderm-derived tissues (placenta and membranes) have been viewed as extraembryonic organs, with the placenta, in particular, described as shared between mother and fetus. But current embryology refutes this position (Sadler et al. 2015). The placenta and membranes interact with maternal tissue, but maternal tissue does not contribute to the placenta or membranes. The embryo generates these tissues in entirety, the embryo is physically continuous with them, and the embryo is genetically identical with them (except in cases of placental mosaicism, which carry the same unimpressive bioethical significance as somatic genetic mutations in an adult). Moreover, the placenta is in fact the embryo's most important vital organ. Fetuses can often survive in utero despite abnormal structure and function of the nervous, cardiovascular, respiratory, urinary, and gastrointestinal systems. In contrast, fetuses thrive in utero in proportion only to the function of their placentas.

Thirdly, moral theologians have articulated a way of understanding acts with morally good and morally evil effects, now commonly called the principle of double effect. Gury and Ballerini (1882) and many later writers (see Aquinas 1920; Mangan 1949) laid out the following four criteria which must be met for an act to be considered licit, although it has an evil effect:

(1) The act itself must be morally good or neutral.

(2) The good effect of the act must be the only effect intended (i.e., the evil effect must not be directly intended, even if it is expected).

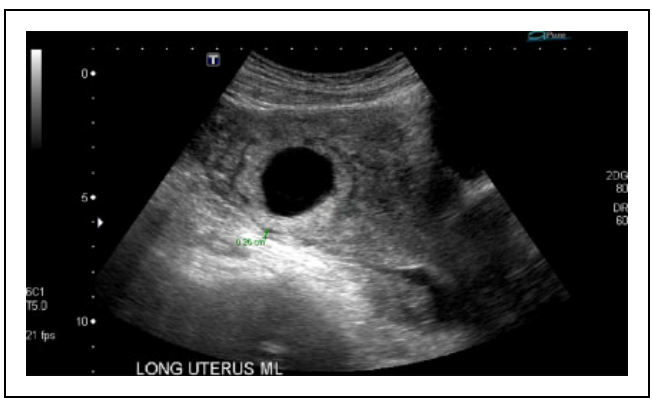

Figure I. Transvaginal ultrasound of case I at nine weeks, midline longitudinal view, illustrating fundal gestational sac with calipers illustrating 0.26 centimeter of myometrium.

(3) The good effect must not be obtained by means of the evil effect.

(4) The good effect must be in proportion to the evil effect.

For example, two types of termination of pregnancy can be defined. A direct abortion is any procedure which intends and achieves the sole immediate effect of embryonic or fetal death. A direct abortion can be caused by physical dismemberment or chemical embryocide. This is never acceptable, even if it is done truly with the medical safety of the mother in mind. In contrast, an indirect abortion is an unintended (even if expected) embryonic or fetal death as a result of a procedure intended to treat pathology of proportionally grave effect, such as something threatening the mother's life. An indirect abortion may involve dismemberment of a nonliving body. An indirect abortion may also involve use of a drug detectable in embryonic tissues, but only when the detected drug did not cause fetal death. An indirect abortion is licit according to the principle of double effect.

\section{Case I: Uncomplicated Surgical Management of Interstitial Pregnancy}

A thirty-six-year-old woman with a history of four pregnancies including one term delivery and three spontaneous abortions which required dilation and curettage (D\&C), was diagnosed with an IP during a routine viability ultrasound (see Figures 1 and 2). She was treated with methotrexate by her primary care provider. She did not respond to medical therapy, with an increase in $\beta$-human chorionic gonadotropin ( $\beta$-hCG) from 17,000 to 34,000 on day 4 . She 


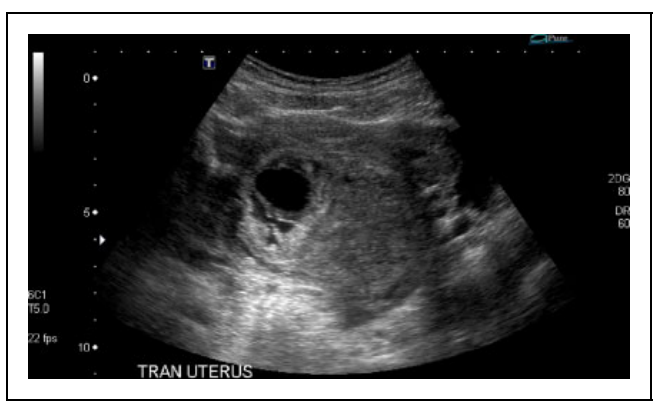

Figure 2. Transvaginal ultrasound of case $I$ at nine weeks, transverse view of the fundus, illustrating asymmetry of gestational sac.

was referred to St. Louis University for surgical management. On repeat ultrasound, the patient was found to have a six-week, zero-day gestation in the right interstitium, with a fetal heart rate slightly lower than normal for gestational age (120 beats per minute). The patient desired future fertility. She consented to diagnostic laparoscopy, removal of IP, and possible hysterectomy. Intraoperatively, the uterus was found to be intact without a uterine window. As the patient desired to preserve future fertility, the decision was made to evacuate the pregnancy via suction D\&C. The patient underwent an uneventful suction D\&C under ultrasound guidance and recovered without incident.

\section{Case 2: Surgical Management of Ruptured Interstitial Pregnancy}

A twenty-seven-year-old woman with a history of four vaginal deliveries (all term except for one at thirty-five weeks) presented to the emergency room three times in her first trimester, complaining of pain and vomiting. She expressed at her initial prenatal visit that she was unsure she could have another vaginal delivery due to her pain. Attempts at controlling her pain with non-narcotics, a bowel regimen, and antiemetics were unsuccessful. She finally presented at seventeen weeks to the emergency department after three episodes of unresponsiveness at home. At the scene, she was unable to answer questions and her systolic blood pressure was $70 \mathrm{mmHg}$. In the emergency department, she was hemodynamically stabilized with crystalloids. She had no peritoneal signs. She was found to be anemic with a hemoglobin of $6.6 \mathrm{~g} / \mathrm{dL}$. A bedside ultrasound illustrated a live pregnancy. Computed tomography of the abdomen and pelvis illustrated hemoperitoneum and an irregular uterine contour (see Figure 3). She

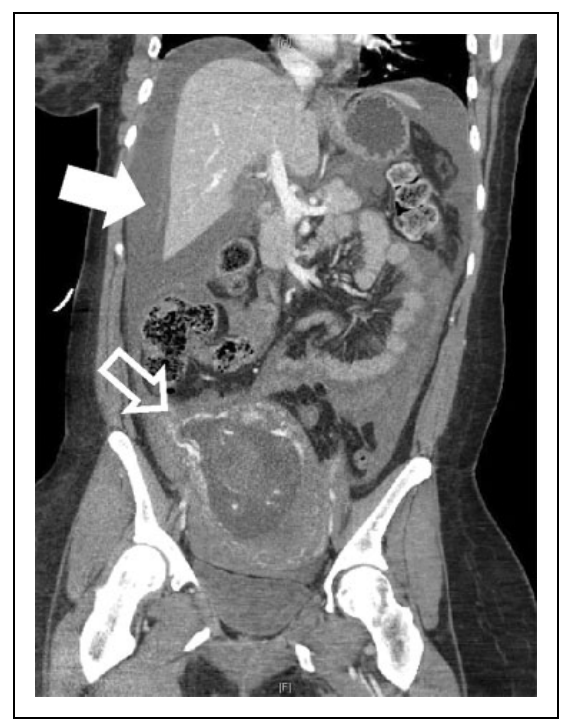

Figure 3. Coronal computed tomography of case 2 at seventeen weeks, showing hemoperitoneum (solid arrow) and protrusion of amniotic sac through right cornu (hollow arrow).

was transfused, but failed to respond appropriately, with hemoglobin dropping to $7.5 \mathrm{~g} / \mathrm{dL}$ after initial rise to $8.7 \mathrm{~g} / \mathrm{dL}$. She was admitted to the intensive care unit for unstable vital signs. Her team consisted of members of the departments of urogynecology, maternal-fetal medicine, generalist obstetrics and gynecology, general surgery, and critical care medicine.

The patient consented to diagnostic laparoscopy, possible laparotomy, and other indicated procedures in order to investigate the cause of her hemoperitoneum and symptomatic anemia. Intraoperatively, she was found to have four liters of blood in the peritoneal cavity. Upon evacuation of hemoperitoneum, there was slow but active bleeding from a distended right cornu, where trophoblastic tissue appeared to be extruding into the peritoneal cavity and partially attached to the right tube. The affected area was thinned and dark with hemorrhage, consistent with Couvelaire uterus. Additional blood products were administered.

The decision was made to convert to laparotomy. A larger placental extrusion was then seen from the anterior lower uterine segment. Intraoperative ultrasound was performed and fetal cardiac activity was noted to be absent. As this was being confirmed with color Doppler by a second physician, the placenta began to extrude further. Membranes began to appear along with the fetus. The thinned lower 
uterine segment began to tear from the extruding tissue despite efforts to maintain intact membranes. Meanwhile, there had been an estimated one liter of blood loss in addition to the original four liters of hemoperitoneum.

A supracervical hysterectomy and right salpingectomy were performed. The patient was found to be coagulopathic intraoperatively with a fibrinogen of $94 \mathrm{mg} /$ dL. Gelfoam, thrombin, and a closed drain were placed. Estimated blood loss was seven liters total. Replacement included ten liters of packed red cells, three units of fresh-frozen plasma, and one unit of cryoprecipitate. The patient recovered in the intensive care unit until postoperative day 2 and was discharged from the floor in stable condition on postoperative day 6 .

\section{Review of the Literature and Ethical Considerations: Interstitial Pregnancy}

This section will list the interventions studied for treatment of IP and follow each description with Catholic ethical principles to guide physicians and hospitals desiring to abide by the Catholic church teaching.

IPs represent 2.5 percent of ectopic pregnancies (Bouyer 2002). They result when a blastocyst implants in the interstitial portion of the fallopian tube, the part of the tube which traverses the myometrium and opens into the endometrial cavity at the tubal ostium (see Figure 4A). ${ }^{2}$ An IP is diagnosed with a positive pregnancy test and ultrasound findings including (1) an empty uterine cavity, (2) a chorionic sac seen more than one centimeter from the lateral edge of the uterine cavity, and (3) a myometrial layer surrounding the chorionic sac less than five millimeters in thickness (Jurkovic et al. 2003). As contractions and fibroids can cause an intrauterine pregnancy (IUP) to appear eccentric and lead to a mistaken diagnosis, it is recommended to rescan possible IPs in a matter of days if the diagnosis is in question. Three-dimensional ultrasound and magnetic resonance imaging can also be helpful when the diagnosis is unclear (Arleo and Defilippis 2014).

Embryos and fetuses in IPs, like those in tubal ectopic pregnancies, are considered nonviable. The natural history of IP is, however, much worse. While tubal ectopic pregnancies are supplied by the ovarian vessels and small anastomoses from the uterine artery, IPs are surrounded by a small amount of myometrium, which is fed by the more powerful uterine artery. There is no normal endometrium in the interstitial tube and the myometrium surrounding an IP is

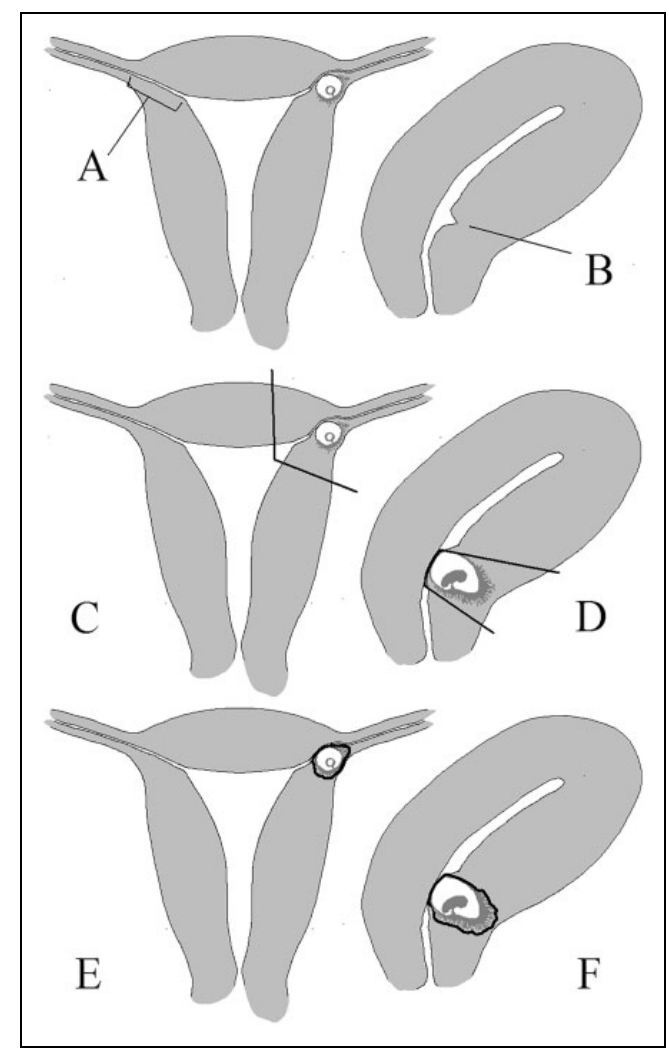

Figure 4. (A) The interstitial portion of the fallopian tube and an interstitial pregnancy diagrammed with a coronal section of the uterus and proximal tubes. (B) A cesarean scar seen with a midsagittal section of the uterus. (C) Schematic of cornual wedge resection. (D) Schematic of scar excision. (E) Schematic of cornuostomy. (F) Schematic of gestational excision.

too thin to contain a viable pregnancy. However, the small amount of myometrium surrounding an IP is capable of blood flow expansion, like the rest of the normal uterine tissue.

Because of their location, IPs have a better blood and tissue supply than extrauterine tubal ectopic pregnancies but still have insufficient nutritional supply to proceed to viability. Although some regress, IPs almost universally rupture between eight and sixteen weeks of gestation, leading to double the mortality of an extrauterine tubal pregnancy (Dähnert 2007). This is because hemorrhage comes not only from ovarian vessels which typically leak slowly, but from uterine vessels, which can empty an adult of blood in thirty minutes at twelve weeks gestation (Bernstein 2002).

Historically, IPs were managed with abdominal hysterectomy or open cornual resection (Te Linde 
2015). Methotrexate was introduced as a medical therapy by analogy to extrauterine tubal ectopic pregnancies. Laparoscopic cornuostomy, salpingostomy, and various cornual excision techniques have replaced open techniques apart from emergent cases with cardiovascular collapse (Chetty and Elson 2009). Newer medical treatments, including etoposide and actinomycin D, have also been used intragestationally, but there is limited information on their safety and efficacy. Several case series and reviews help delineate the most common therapies used today.

\section{Expectant Management}

Seven interstitial pregnancies have been managed expectantly and led to viability and delivery (Samal and Rathod 2015). This is by far exceptional. Expectant management, with appropriate precautions, may be acceptable for a stable, reliable patient with declining $\beta$-hCG values. The standard of care in medical literature for the remainder of cases is termination of pregnancy (Arleo and Defilippis 2014).

Expectant management is often a safe haven for Catholic OB/GYNs who do not wish to interfere with ectopic pregnancies and Catholic patients who do not wish to impact their fertility. With IP in reliable patients with declining $\beta$-hCG values, expectant management is likely a safe starting plan. However, there is a greater risk of hemorrhage in IP due to the dual blood supply, from the ovarian and uterine vessels. Additionally, IP threatens to rupture the uterus, while tubal ectopic pregnancies threaten a smaller and duplicated organ. The risk of emergent hysterectomy and loss of fertility is much higher in IP. Expectant management should not be a first-line option for large IP, rising $\beta$-hCG values, or acute presentations.

\section{Systemic Methotrexate}

Intramuscular methotrexate has been demonstrated as effective for the termination of CSP when mean gestational sac diameter (MSD) is small; $2.3 \pm 1.2$ centimeters in one review (Lau and Tulandi 1999). A more recent review noted successful medical treatment in 94 percent of patients with $\beta$-hCG of $<5,000$ IU/L, regardless of cardiac activity. These patients received a single intramuscular dose of $50 \mathrm{mg} / \mathrm{m}^{2}$ of methotrexate and a second dose if the $\beta$-hCG failed to drop 15 percent between days 4 and 7 (Jermy et al. 2004). Intravenous methotrexate has also been used, with a success rate of ninety-one percent (Tang Baartz, and KeatKhoo 2006). Medical literature recommends that patients who fail to respond to initial methotrexate dosing should either receive repeat doses or move to surgical management, as a single-dose regimen of methotrexate in IP has four times the odds of failing when compared to extrauterine tubal pregnancy (Moawad et al. 2010). Systemic methotrexate is contraindicated in IP under the same conditions as extrauterine tubal pregnancy, especially in hemodynamic instability and tubal or uterine rupture.

Catholic ethicists are divided on the issue of methotrexate administration because it appears to act like a direct abortifacient. Pharmacological studies demonstrate that it primarily affects the trophoblast (Stika 2012). The trophoblast is arguably the only vital organ of the embryo (Sadler et al. 2015), and a drug that targets a person's only vital organ is difficult to defend.

Some argue that the trophoblast, although healthy, is ectopic, and this constitutes a diseased state that merits treatment (Ashley and O'Rourke 2002; De Blois et al. 1994). Ectopic pregnancy presents one of the only instances of one person's vital organ being ectopic in another person's body. Should dangerous ectopia be treated as it is within one person with resection? Answering this question is beyond the scope of this review. While the church leaves unsettled issues, such as the prescription of methotrexate, to the conscience of a faithful Catholic physician, it is a medical fact that the trophoblast or placenta is a vital organ of the developing embryo or fetus. Administration of a chemical targeted to destroy this organ seems indefensible.

\section{Intragestational Methotrexate}

Ultrasound-guided percutaneous administration of methotrexate into the gestational sac is also a documented treatment of interstitial pregnancy. Physicians may choose to perform needle aspiration of products of conception (POC) ${ }^{3}$ before methotrexate injection; for this procedure, general anesthesia is administered because a sixteen-gauge, doublelumen in vitro fertilization needle is used to aspirate POC transvaginally.

Intragestational methotrexate is $91-100$ percent successful in appropriate patients, such as those with MSD less than 3.6 centimeters (Moawad et al. 2010; Lau and Tulandi 1999). Dosing regimens have not been directly compared, but examples of regimens used are $1 \mathrm{mg} / \mathrm{kg}, 12.5 \mathrm{mg}$, or $100 \mathrm{mg}$ fixed doses, and the traditional $50 \mathrm{mg} / \mathrm{m}^{2}$. More studies are needed to correlate dosage with clinical findings in order to maximize success rates. 
This option leaves maternal anatomy intact. In fact, when considered together with potassium chloride (see below), 91.7 percent of treated women have ipsilateral tubal patency after resolution of the pregnancy (Moawad et al. 2010). Rates of recurrent ipsilateral IP have not been studied.

The ethics of intragestational methotrexate are in one way no different from that of systemic methotrexate: it is the same chemical that invites the same debate. However, there are two additional concerns. Firstly, aspiration of POC prior to placement of methotrexate raises concerns of fetal injury. Aspiration is documented in most cases of intragestational methotrexate administration, and this step in the procedure may be responsible for part of the success of this treatment modality. If the fetal body is injured or if death occurs due to the act of suctioning the fetus onto the needle, this constitutes an attack on the fetus or a direct abortion. Aspiration prior to intragestational methotrexate should thus be viewed with caution; if it is necessary, ultrasound guidance should guarantee fetal integrity.

Secondly, it is theoretically possible that when methotrexate is placed in the amniotic cavity (especially if amniotic fluid is aspirated and there is little dilution), it has a greater action on the fetal body than it would when traveling systemically toward the fetus through the trophoblast. More research is needed in this area before intragestational methotrexate can even be considered by faithful Catholics.

\section{Intragestational Potassium Chloride}

Two reviews discuss the use of potassium chloride $(\mathrm{KCl})$ administration for IP; two cases of successful treatment of IP are documented, and this may be theoretically selective in heterotopic pregnancies (i.e., where there is one IP and one IUP). As noted above, there is a 91.7 percent ipsilateral tubal patency rate when intragestational $\mathrm{KCl}$ and intragestational methotrexate are analyzed together (Moawad et al. 2010).

The ethics of $\mathrm{KCl}$ will not be discussed in detail. The only purpose of $\mathrm{KCl}$, whether injected into the amniotic cavity, cord, or embryo, is embryonic asystole. It is a direct abortifacient, and its use is gravely immoral.

\section{Uterine Artery Embolization}

Uterine artery embolization (UAE) is performed by an interventional radiologist under local anesthesia. Using a catheter advanced through the femoral artery, the radiologist approaches the uterine artery under fluoroscopic guidance. Occlusive material is fed through the catheter to block off the uterine artery or one of its branches feeding the IP. Prior to the occlusion, the radiologist may also place methotrexate through the catheter, which supplies a higher concentration of methotrexate to the IP than does intramuscular administration. A woman who has undergone UAE can become pregnant again (Ravina et al. 2000). Studies of bilateral UAE for fibroids, however, show that UAE may decrease ovarian reserve and dispose a woman to abnormal placentation in future pregnancies (Hehenkamp et al. 2007; Pron et al. 2005).

Selective UAE, on the side with the IP, has yielded success in several case reports. However, due to the large number of anastomotic vessels supplying the uterine cornu (i.e., since there is still a patent uterine artery and ovarian vessel), it is theoretically less definitive than other options and is still considered experimental (Moawad et al. 2010). There is no data regarding pregnancy after unilateral UAE, but there may be fewer adverse effects on fertility and placentation as only part of the uterine blood supply is being sacrificed.

Unilateral UAE for IP intends to end the pregnancy by means of ischemia surrounding the trophoblast, while preserving maternal anatomy. A sign of this is that UAE is deemed to "fail" when the fetus does not die. Thus, unilateral UAE for IP constitutes a direct abortion. Additional discussion of bilateral UAE, which can sometimes constitute an indirect abortion, may be found below.

\section{Dilation and Curettage}

$\mathrm{D} \& \mathrm{C}$ is a simple and common procedure which is done frequently by Catholic OB/GYNs for missed abortions (embryonic or fetal demise without passage of POC) as well as bleeding outside of pregnancy. A D\&C is done under general anesthesia or monitored anesthesia care. During this, the cervix is progressively dilated with metal instruments. Then, either a blunt plastic suction cannula or a set of metal curettes is used to scrape the endometrium and anything attached to it out of the uterus. The cannula and the curettes are about as sharp as a table knife, but the uterine contents are taken out in pieces. (Endometrium and POC are very soft, and the cervix is only open a few millimeters to allow material to pass through.)

A D\&C can be done with or without ultrasound guidance. A D\&C is typically an outpatient surgery unless intraoperative blood loss is significant or a uterine perforation causes injury to adjacent organs requiring additional intervention. 
An IP can be removed through the cervix with a $\mathrm{D} \& \mathrm{C}$, but this is rarely done. It has been successfully used in six published cases, either by suction cannula or sharp curettage, with or without laparoscopic supervision, and either removing all POC or leaving the placenta in situ. (Leaving the placenta is thought to minimize the risk of uterine perforation, a common complication of sharp curettage in pregnant uteri, especially with a thinned cornu; Moawad et al. 2010.)

D\&C for IUP represents a direct abortion: a living human person is divided into pieces in order to end his life. According to Catholic teaching and natural law, this is never acceptable, regardless of the consequences of continuing pregnancy. A difference in the location of the person (IUP vs. IP) does not change what is happening to him. A difference in maternal risk from continuing pregnancy also does not change the morality of a D\&C: ends (preserving life) cannot justify the means (intentionally destroying life). Some might hope that the principle of double effect can apply here, but it cannot due to the express intention of the gynecologist to end the pregnancy in $\mathrm{D} \& \mathrm{C}$.

$\mathrm{D} \& \mathrm{C}$ is thus never appropriate for living fetuses in IP but may be considered if there is moral certainty regarding embryonic or fetal death. While criteria exist for moral certitude in spontaneous abortion of IUP (Campion et al. 2013), there are no criteria in IP. For moral certitude, absence of cardiac motion should be documented when cardiac motion was previously appreciated before considering $\mathrm{D} \& \mathrm{C}$. However, it must be noted that $\mathrm{D} \& \mathrm{C}$ is not the preferred or most studied procedure in IP regardless of fetal status.

\section{Cornuostomy}

Cornuostomy is analogous to salpingostomy or salpingotomy (see Figure 4E). This can be done via laparotomy but is increasingly done laparoscopically (Ng et al. 2009; Moawad, Dayaratna, and Mahajan 2008). In the largest case series of laparoscopic management of IPs, cornuostomy was performed for cornual pregnancies of approximately two centimeters or less. A hemostatic suture, intrauterine vasopressin, intrauterine norepinephrine, or a combination of these may be used prior to uterine incision to promote hemostasis. A linear incision is made across the distended cornu of the uterus, and POC are pushed out or removed with blunt or sharp dissection, or hydrodissection (Moawad et al. 2010). In a laparotomy, POC are passed off as they are removed, either intact or in pieces. In laparoscopy, POC may be removed intact in an endosurgical bag or in pieces through a trocar. The cornual defect is then closed with running or interrupted sutures, a purse-string stitch or surgical glue; alternatively, it may be left to heal by secondary intention if hemostatic (Moawad et al. 2010).

Following cornuostomy, $\beta$-hCG values are monitored and methotrexate is given as needed. Quantitative serum $\beta$-hCG is monitored until it drops to zero. In a series of both cornuostomy and cornual wedge resection, 17 percent of patients required adjuvant methotrexate. The pregnancy rate following these procedures is 34 percent, but 7 percent of these are recurrent IPs (Ng et al. 2009). Notably, surgery is the optimal option for patients with recurrent IP to empirically treat likely maternal pathology that continues to promote ectopia.

Discussion of cornuostomy resembles the discussion of salpingostomy. There is still debate among bioethicists and physicians regarding the appropriateness of salpingostomy, and this rich and well-meaning debate is difficult to distill. Briefly, proponents of salpingostomy argue that its purpose is removal of pathological tissue (ectopic placenta), constitutes an abortion by removal (indirect abortion), preserves the good of fertility, and is morally neutral (as this removal would be a necessary step in a good procedure such as ectopic rescue; Kaczor 2009; May 2008; Ashley and O'Rourke 2002; De Blois 2002). Opponents reply that the trophoblast is a vital organ of the embryo, fertility is not proportional to the evil of embryonic death, there is no current ectopic rescue, and POC are frequently taken out piecemeal from salpingostomies (not a true "removal," but a direct abortion, a death by dismemberment; May 1994; DeGoede 2014; Hager 2016).

It is beyond the scope of this review to settle this question. However, three important distinctions regarding cornuostomy should be discussed. Firstly, the risk of resecting a portion of the uterus is much higher than the risk of resecting a tube. Salpingectomy is a technically easier procedure than salpingostomy; in contrast, cornuostomy is a technically easier procedure than cornual wedge resection (described below). Secondly, the more significant a uterine incision, the more morbidity the patient risks in future pregnancies. Admittedly, this does not change the objective nature of the act, but it does prompt physicians to consider cornuostomy more seriously if the fetus can be removed without dismemberment.

Thirdly, cornuostomy (as well as wedge resection) uses a form of hemostasis prior to incision. This 
may involve a purse-string suture to physically constrict vessels but more commonly involves a chemical vasoconstrictor such as vasopressin (less commonly, epinephrine). The use of vasopressin surrounding a pregnancy has not yet been discussed in Catholic bioethical literature.

These interventions require discussion because constriction of blood supply to the implantation site can cause trophoblastic or placental ischemia followed by embryonic or fetal anoxia, acidemia, and death. During cornuostomy or cornual wedge resection, vasopressin is injected around the pregnancy circumferentially, to prevent maternal blood loss once the incision(s) is (are) made. It is almost certain that some vasopressin affects fetal tissues and enters fetal circulation. If the fetus expresses vasopressin receptors (or adrenergic receptors in the case of epinephrine), this can also lead to physiologic changes in the fetus. No safe drug levels of vasopressin or epinephrine have been established in the first trimester and early second trimester, but animal embryos have been documented to express vasopressin receptors at as early as twelve conceptional days, and adrenergic receptors before implantation (Chen, Schreiber, and Brinton 2000; Čikoš et al. 2013).

The principle of double effect can apply to vasopressin and epinephrine use if the surgeon is careful to avoid administering excessive amounts to the fetus. The act of injecting vasoconstrictors for preventative hemostasis is morally neutral. Any fetal vasoconstriction, hypoxia, or acidemia that results is not the means by which hemostasis is achieved, but an accidental effect. Finally, there is a proportion between maternal hemostasis and fetal acidemia. Without hemostasis, significant bleeding in fact leads to the same problem in the mother as the fetus potentially faces: low blood volume leads to brain, renal, and cardiac hypoxia, followed by acidemia. Blood loss rarely leads to death due to modern transfusion and critical care medicine; in a similar way, intrauterine vasopressin is rarely the main threat to fetal death when the fetus is being removed from its ectopic site.

But if a significant amount of vasopressin is used and it is heedlessly placed very close to the gestational sac, there is significant risk of fetal death, not just hypoxia or acidemia. There is no proportion between maternal hemostasis and certain fetal death. Care must be used to minimize the risk of fetal death due to vasopressin administration, so that the principle of double effect can continue to apply.

\section{Salpingostomy}

When anatomically feasible, a surgeon may elect to incise the tube rather than the myometrium and remove an IP through the tube. This has the advantage of avoiding the morbidity of a hysterotomy: every uterine incision poses risks in future pregnancies (i.e., abnormal placentation and uterine rupture). One review documents salpingostomy as an option in early IP, but notes that it may be difficult to see the implantation site and guarantee complete placental resection. The author of that review suggests the use of adjuvant methotrexate based on analogy to extrauterine tubal pregnancy until $\beta$-hCG reaches zero (Moawad et al. 2010).

The ethical discussion of salpingostomy above suffices for this section. It must be noted that in IP, salpingostomy has slightly different significance than in extrauterine tubal pregnancy because an incision on the fallopian tube confers less risk of future pregnancies than a uterine incision. Given a reliable patient, a low starting $\beta$-hCG and surgeon confidence that all POC can be removed through the tube, salpingostomy might be the lowest risk procedure with a high success rate. If a physician can do this with moral certitude that the fetal body is not dismembered, then this may be an acceptable choice.

\section{Cornual Wedge Resection}

Cornual wedge resection, also called cornual excision or cornual resection, is analogous to salpingectomy (see Figure 4C). In the largest case series to date, this procedure was usually chosen for IPs greater than 3 centimeters in diameter, but other studies have advocated cutoffs of 3.5 or 4 centimeters ( $\mathrm{Ng}$ et al. 2009; Tulandi, Vilos, and Gomel 1995; Grobman and Milad 1998). Again, this is increasingly being performed laparoscopically (Nirgianakis et al. 2016). Like in cornuostomy, a suture or vasoconstrictive medication is placed to prevent blood loss obscuring the operative field. The uterine muscle is incised and the cornu of the uterus in which the pregnancy has implanted is resected en bloc. This incision can be performed with an endoloop or cautery (Moon et al. 2000; $\mathrm{Ng} 2009)$. The specimen is removed intact or in pieces, depending on its size and the surgeon's preference. Removal of the ipsilateral tube, if it is present, is performed if there is significant damage to the structure, or as a prophylactic measure to prevent future tubal pregnancy. The defect is then sewn shut.

Following cornual wedge resection, $\beta$-hCG values are monitored until they reach zero, and methotrexate is given as needed. In the abovementioned series of cornuostomy and cornual wedge resection, 17 percent of patients who underwent one of these procedures needed subsequent methotrexate. The 
pregnancy rate was 34 percent in that series and the recurrence of IP was 7 percent ( $\mathrm{Ng}$ et al. 2009). Spontaneous dehiscence of the wedge repair has been documented (Wye et al. 2014). Reconstruction of vulnerable repairs has resulted in live births, but rupture may occur as the pregnant uterus expands (Maruthini and Sharma 2013; Chatterjee et al. 2009).

Wedge resection constitutes a clear indirect abortion, which can be seen by analogy to hysterectomy. In cases of uterine or cervical cancer requiring hysterectomy during pregnancy, hysterectomy is permissible according to the principle of double effect: the result is an indirect abortion, which is not the expressly desired effect, and which is proportional to the mother's avoidance of death by cancer. Analogously, when a uterine cornu harbors an ectopic pregnancy and may burst and lead to hemorrhage and death, the entire cornu may be resected with the pregnancy in situ.

\section{Hysterectomy}

Hysterectomy, the historical treatment of choice for 50 percent of IPs, is now relegated to women with uncontrollable bleeding, very large IPs, or failure of another surgical procedure. One review suggests that a woman who does not desire future fertility or who has other uterine pathology may elect to have a hysterectomy if she is discovered to have an IP (Moawad et al. 2010).

Hysterectomy appears attractive to Catholic OB/ GYNs for similar reasons as expectant management: it is an ethically safe haven. Hysterectomy would lead to an indirect abortion by removal of the embryo from his or her mother. But it should not be forgotten that hysterectomy should generally be avoided in order to preserve fertility. Because there are less radical treatments available, hysterectomy should be reserved as a rescue operation when no other avenue that has moral certitude is available. Finally, the decision to proceed with hysterectomy should not be influenced by a patient's desire for no future fertility. This muddies the intention to avoid primary sterilization.

\section{Case 3: Medical and Surgical Management of CSP}

A twenty-five-year-old woman with a history of four prior cesarean sections presented to an outside hospital with vaginal bleeding, pelvic pain, and a positive pregnancy test. There, she was told she had a sixweek CSP that would require injection of $\mathrm{KCl}$ into the gestational sac. She presented to St. Louis

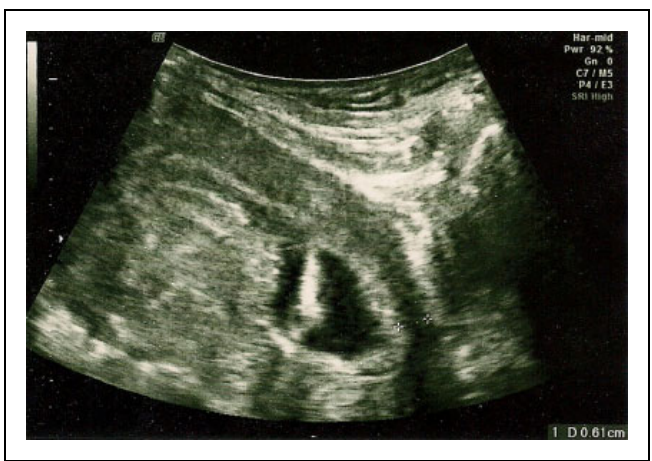

Figure 5. Transvaginal ultrasound of case 3 at seven weeks, documenting absent fetal cardiac activity after methotrexate administration. Calipers highlight 0.61 centimeter of myometrium anterior to the gestational sac, thickened from previously distended imaging.

University for a second opinion because, in her words, "I didn't want to kill my baby."

Transvaginal ultrasound documented a yolk sac and embryonic pole in the lower uterine segment, which was separated from the bladder by two millimeters of myometrium. The endometrial stripe and cervical canal were not involved. Measurements were consistent with a six weeks and four days type II CSP. The patient desired future fertility, and she elected systemic methotrexate, which was administered $1 \mathrm{mg} / \mathrm{kg}$ every other day, alternating with leucovorin $0.1 \mathrm{mg} / \mathrm{kg}$ every other day. Quantitative $\beta$-hCG was measured on the days of methotrexate administration, and electrolytes and complete blood counts were measured on the days of leucovorin rescue. The goal of therapy was decrease in $\beta$-hCG by 15 percent before discharge home, then outpatient therapy. On day 4 of the multidose methotrexate regimen, the fetus was found to have absent cardiac activity on bedside ultrasound (see Figure 5). The patient accepted this news peacefully, having already begun grieving the loss of her unborn child.

On day 4, the patient's alanine transferase (ALT) was slightly elevated to 102 (range $12-78 \mathrm{U} / \mathrm{L}$ ). On day 5 , the $\beta$-hCG was 50,720 up from the initial 47,042 . On day 6 , the patient's ALT and aspartate transaminase (AST) were both elevated with ALT 209 and AST 84 (range 5-40 U/L). Due to her elevated liver function tests, methotrexate was held; as a result, $\beta$-hCG increased from 50,720 to 55,719 IU/L between days 5 and 7 . The methotrexate was continually held, but liver function did not return to baseline while $\beta$-hCG continued to plateau. The patient was counseled regarding the need for a 
different treatment direction, changing chemotherapeutic agents (actinomycin D was the most viable second option), injection of methotrexate into the gestational sac, or surgical management. She agreed to proceed with surgery to remove the POC (the fetus by then being without heart tones for six days). The patient underwent an uneventful D\&C with simultaneous laparoscopy and recovered without incident.

\section{Case 4: Surgical Salvage of CSP}

A thirty-three-year-old woman presented in the eighth week of her second pregnancy. Her first pregnancy was complicated by fetal anomalies and fetal distress remote from delivery, which prompted a cesarean section at term during induction of labor. The child born died from a rare congenital syndrome shortly after birth. The patient intensely desired a child and was crestfallen to hear at her dating ultrasound that she had a CSP. Further transvaginal ultrasound with filled bladder characterized an expanding gestational sac into and through a very thin anterior uterine wall, characteristic of a type II CSP.

The patient was counseled on termination and reluctantly agreed to a $\mathrm{D} \& \mathrm{C}$ with simultaneous laparoscopy to ensure no injury to intraabdominal organs, especially the bladder. However, a second opinion was given, offering laparoscopic oversewing of the hysterotomy. She elected to accept the risks of this experimental pregnancy salvage.

The repair was successful: the lower uterine segment, which had measured one millimeter, measured ten millimeters in thickness after imbrication. She was admitted at twenty-eight weeks for close surveillance and imaging (see Figure 6). Upon spontaneous rupture of membranes at thirty weeks and six days, she underwent cesarean section and required cesarean hysterectomy for control of bleeding due to placenta percreta. The estimated blood loss during the procedure was sixteen liters. She recovered in the surgical ICU and was discharged in stable condition. Her baby had outcomes similar to other thirty-one-week infants and initially required continuous positive airway pressure and tube feedings. He transitioned to room air and oral feedings by two weeks of life. This case, including final neonatal disposition, will be more completely and formally described under separate cover.

\section{Review of the Literature and Ethical Considerations: CSP}

Theoretically, any uterine incision can lead to abnormal implantation into scar tissue rather than normal

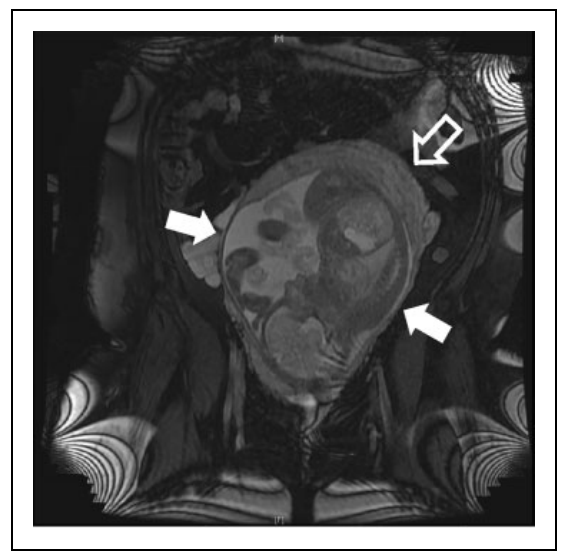

Figure 6. Coronal magnetic resonance imaging of case 4, coronal view, at twenty-nine weeks. The amniotic cavity (former gestational sac) has expanded the lower uterine segment (solid arrows). Thick, unused uterine fundus can be seen at the top of the gestational sac (hollow arrow).

endometrium; however, since cesarean section represents the most common hysterotomy, CSP is the entity discussed here (see Figure 4B). Now that single-layer uterine closure is more common in some areas, and since the rate of cesarean section is so high (up to 40.5 percent in Latin America and the Caribbean), the incidence of CSP is increasing (Betrán et al. 2016). It is estimated to occur in 1 in every 531 women with a cesarean scar and in 4.2 percent of ectopic pregnancies (Fylstra 2002).

CSP is diagnosed with a positive pregnancy test, an empty uterus and cervix, and a gestational sac embedded in the anterior uterine wall with five or fewer millimeters of myometrium between the gestational sac and the woman's bladder (Rotas, Haberman, and Levgur 2006). The gestational sacs of CSPs are occasionally triangular. CSPs may be classified into two types. Type I CSP is a pregnancy implanted in the scar, but growing into the endocervical and endometrial space. In contrast, type II CSPs grow toward the uterine serosa, away from the endometrium. Type I CSPs can proceed to term, but still carry higher risks of maternal morbidity and mortality, with high risks of placenta accreta, increta, and percreta as well as uterine rupture and life-threatening hemorrhage (Collins and Kothari 2015). Type II CSPs are considered nonviable.

CSPs confer a greater risk of hemorrhage compared to extrauterine tubal ectopic pregnancies. This is largely because CSPs are located at the level of the uterine arteries, which are much larger than the 
anastomoses supplying the fallopian tubes. Of 751 cases of CSP in a recent review, there were 36 emergent hysterectomies, 40 emergent laparotomies, and 22 rescue UAEs to prevent death from hemorrhage (Timor-Tritsch and Monteagudo 2012). This is due in part to delay in diagnosis; 13.6 percent of CSPs are misdiagnosed as IUPs, cervical pregnancies, or spontaneous abortions (Timor-Tritsch and Monteagudo 2012). The higher the gestational age, the greater the risk of maternal morbidity, even with successful treatment: morbidity and complications rise sharply after seven weeks gestational age (TimorTritsch and Monteagudo 2012).

There have been over thirty suggested therapeutic measures for CSP including procedures, medications, and many combinations of the two (TimorTritsch and Monteagudo 2012). The most frequent medications used are intragestational $\mathrm{KCl}$, systemic or intragestational methotrexate, and systemic mifepristone. Procedural approaches include placement of double-balloon catheter, UAE, hysteroscopy, D\&C, open approaches, and laparoscopy. Less invasive approaches, such as hysteroscopy and D\&C, are either performed blind or guided by ultrasound or simultaneous laparoscopy. Other less welldescribed approaches include expectant management, intragestational vasopressin, transrectal aspiration, etoposide, and trichostatin. There have been no studies large enough to compare all thirty odd approaches, but three recent reviews summarize the following findings about the most common treatments. Each review defines "complication" slightly differently, so numbers should not be compared one to one without inspecting the original reviews.

\section{Expectant Management}

Expectant management has resulted in cases of successful pregnancy in type I CSPs (up to nine out of ten patients in one review), but the cesarean hysterectomy rate at delivery is exceedingly high due to morbidly adherent placenta, uterine rupture, and life-threatening hemorrhage (TimorTritsch et al. 2014; Kanat-Pektas et al. 2016). The complication rate during pregnancy and delivery in one review was 54.5 percent (Timor-Tritsch and Monteagudo 2012). The recommendation of medical experts is to offer the patient termination of pregnancy and the option of continuing type I CSP with close clinical and sonographic surveillance. According to one author:

If the latter is chosen, [the patient] should be advised that [her] chances of achieving the desired delivery (usually premature) of live offspring should be weighed against the significantly high risks of premature delivery, hysterectomy and permanent loss of fertility, and particularly the risks of uterine rupture, massive blood loss, shock and even death. (Timor-Tritsch et al. 2014)

Ethical considerations should take into account these recommendations. Catholic physicians may offer their patients expectant management of demised CSP, followed by medical or surgical management if $\beta$-hCG values fail to regress to zero. Like IP, CSP threatens to rupture the uterus, while tubal ectopic pregnancies threaten a smaller and duplicated organ. Loss of fertility is much more likely with CSP compared to extrauterine tubal ectopic pregnancies. Expectant management of demised or type I CSPs may be offered after informed consent is obtained, and only then with serious precautions and frequent surveillance.

\section{Systemic Methotrexate}

This was the first medical treatment adopted for CSP by analogy to tubal ectopic pregnancy and may be considered in hemodynamically stable patients at eight or fewer weeks gestation, with quantitative $\beta$-hCG measurements less than or equal to 5,000 IU/L, no embryonic cardiac motion, and a gestational sac no greater than 2.5 centimeters in diameter (Petersen et al. 2016). It can be given intramuscularly in a 50-mg dose and monitored as with tubal pregnancies, or multidose regimens can be used, even employing leucovorin rescue. Unfortunately, systemic methotrexate is only successful in 8.7 percent of cases, and it carries a 13 percent complication rate (Kanat-Pektas et al. 2016). The most frequent procedure used after failed systemic methotrexate is $\mathrm{D} \& \mathrm{C}$ (see below), but this combination also has a high complication rate (Kanat-Pektas et al 2016; Timor-Tritsch and Monteagudo 2012). The hysterectomy rate is 3.6 percent following systemic methotrexate usage for primary treatment (Kanat-Pektas et al. 2016). Its failure as a primary treatment has been attributed to its slow distribution and effects. Women with fewer prior cesarean sections do worse with systemic methotrexate as a primary intervention, as their scars are theoretically better vascularized (Kanat-Pektas et al. 2016).

As noted above in discussion of IP, there is still some debate on the use of methotrexate in live ectopic pregnancies, which is beyond the scope of this review. In any case, a review of the obstetrical literature illustrates that systemic methotrexate is not a 
first-line option for CSP. Its relatively high failure and complication rates expose the mother to potential drug toxicity unnecessarily.

\section{Intragestational Methotrexate}

Methotrexate is also commonly administered into the gestational sac, either by placing a twenty- to twenty-two-gauge needle through the abdomen or through the wall of the vagina under local anesthesia. Up to 50 milligrams of the drug can be given this way, which leads to a higher concentration of methotrexate at the trophoblast. The complication rate for local methotrexate is 11-12.5 percent, which was the lowest of all treatments in the review that reported a complication rate (Timor-Tritsch and Monteagudo 2012). Combining local methotrexate with systemic methotrexate led to less predictable results, with complication rates between 5.3 percent and 15.4 percent (Timor-Tritsch and Monteagudo 2012). The differences between these complication rates were not analyzed for statistical significance due to the small sizes of some of the original studies. When needle aspiration and local methotrexate are combined, 13.5 percent of women suffer major complications, and 15.5 percent require additional treatment (Petersen et al. 2016).

Unlike in IP, intragestational methotrexate is demonstrably more successful than systemic methotrexate in CSP. If this option is ethically acceptable, this is a successful, minimally invasive, and lowtoxicity management choice. The concerns with aspiration of live pregnancies discussed above apply also to CSP. In addition, as noted above, intragestational methotrexate may have a different mechanism of action than systemic methotrexate, and this requires investigation prior to its use.

\section{Intragestational Potassium Chloride}

One review discussed the use of intragestational $\mathrm{KCl}$ for heterotopic pregnancies (multiple gestations with one or more intrauterine embryos and a CSP). Intragestational $\mathrm{KCl}$ carried a 0 percent complication rate in eight cases of heterotopic CSP (Timor-Tritsch and Monteagudo 2012).

The ethics of $\mathrm{KCl}$ require no extensive discussion. As noted above, $\mathrm{KCl}$ is a cardiotoxin and is always a direct abortifacient.

\section{Double-Balloon Catheter Placement}

One prospective trial of women with CSP and cervical pregnancy documented resolution of $\beta-\mathrm{hCG}$ in ten patients using a double-balloon transcervical catheter, such as those used for cervical ripening. The balloons were inflated under ultrasound guidance to restrict blood flow or mechanically compress the gestational sac until fetal cardiac motion was absent. Patients retained the balloon for a number of days until it could be deflated without cardiac activity or active bleeding (Timor-Tritsch et al. 2016). It is unclear how this catheter leads to fetal death: it may restrict blood supply or may directly compress the fetal body. In either case, the purpose of placement is openly to achieve a direct abortion.

\section{Uterine Artery Embolization}

When used by itself, UAE has a success rate of 18.3 percent and an 80-82 percent complication rate including a 1.1-percent rate of hysterectomy (Kanat-Pektas et al. 2016; Timor-Tritsch and Monteagudo 2012). When UAE is combined with $\mathrm{D} \& \mathrm{C}$ and methotrexate, additional treatment is needed in 31.4 percent of patients because of treatment failure, and there is a 2.8 percent severe complication rate. When combined with D\&C alone, UAE has a 3.4 percent complication rate, and 6.4 percent of patients need additional treatment. When combined with D\&C and hysteroscopy, the success rate rises to 95.4 percent, and the complication rate drops to 1.2 percent (Petersen et al. 2016). The general consensus is that UAE alone should not be a primary treatment, rather it should be employed either as a rescue operation for bleeding or as a primary prevention of bleeding from myometrial arteriovenous malformation (Timor-Tritsch and Monteagudo 2012; Kanat-Pektas et al. 2016; Petersen et al. 2016).

When used as a primary therapy in the rare cases that this is prudent, UAE would constitute a direct abortion. The intention is to end the pregnancy by means of ischemia surrounding the trophoblast, while preserving maternal anatomy. A sign of this is that UAE used as primary therapy is deemed to "fail" when the fetus does not die.

UAE used as a rescue operation constitutes an indirect abortion, as the intention to save the mother's life by means of blocking the hemorrhaging vessel has the expected simultaneous evil effect of ending the embryonic life. (It should be noted that with serious maternal hypotension, many pregnancies end in spontaneous embryonic or fetal death, and it would be difficult to tell whether this occurred as a result of hypotension or as a result of UAE.) 
As discussed above, UAE confers an increased risk of subfertility and abnormal placentation in future pregnancies. Thus, UAE may constitute a "serious reason" to avoid future pregnancies for some couples, prompting counseling in effective family planning according to the teachings of the church (Paul VI 1993). Notably, the decision to use UAE should not be influenced by a patient's desire for no future fertility. This muddies the intention to avoid primary sterilization.

\section{Dilation and Curettage (or Extraction)}

D\&C is described above. In certain cases, CSPs may persist to the second trimester and require dilation and extraction (D\&E), which is identical to D\&C except in the instruments used and the risk of lacerating the mother's cervix and uterus with fetal bony parts. Either procedure would be followed by serial $\beta$-hCG measurements to ensure removal of all trophoblastic tissue. The medical literature on CSPs does not divide $\mathrm{D} \& \mathrm{C}$ and $\mathrm{D} \& \mathrm{E}$, so these will be discussed together as "D\&C."

When used for CSP, D\&C has a serious complication rate of 21 percent and succeeds without additional treatment in only 48.1-61.6 percent of cases (Petersen et al. 2016; Kanat-Pektas et al. 2016). Emergent UAE is needed in 60.7 percent of complicated cases and emergent hysterectomy is required in 7.3 percent of cases (Kanat-Pektas et al. 2016). The general recommendation is to avoid $\mathrm{D} \& \mathrm{C}$ as a primary treatment for CSP due to its risks of bleeding as well as the relatively poor return of fertility and poor future obstetric performance following D\&C (Kanat-Pektas et al. 2016). If D\&C must be done or is considered the best initial therapy, blood products should be available and a Bakri balloon may be placed postoperatively as prophylaxis (Kanat-Pektas et al. 2016).

The ethical discussion of D\&C for CSP is identical to the discussion for IP above. D\&C for an IUP represents a direct abortion: a living human person is divided into pieces. This is never acceptable. As with evacuation of IP (see above), a difference in the location of the person hardly changes what is happening to him, even when higher maternal risks are considered. However, it should be noted that if spontaneous abortion or fetal demise can be documented with moral certitude, a D\&C or D\&E is morally acceptable. Criteria for diagnosis of embryonic demise in IUP (Campion et al. 2013) should only be applied with caution in these cases due to the anatomic distortions in CSP. The author again suggests performing D\&C only when there is absence of cardiac motion after such motion was previously documented.

\section{Hysteroscopy}

Hysteroscopy involves visualization of the uterine cavity using a camera placed through the cervix; operative hysteroscopy involves use of instruments placed through ports in this camera or the use of specially designed hysteroscopic instruments with capabilities for cautery or mechanical morcellation. This requires a competent surgeon and appropriate surgical staff and supplies. Hysteroscopy can be used in two ways in CSP: diagnostic hysteroscopy can be used to inspect the endometrial cavity and cesarean scar, and operative hysteroscopy can be used to resect the POC. Importantly, material removed through a hysteroscope (a tube with diameter under a centimeter) is removed in pieces.

Hysteroscopy appears to be the safest primary treatment with a complication rate of 3.2 percent. However, 17 percent of women needed additional treatment (Petersen et al. 2016). Some have described using a Bakri balloon prophylactically to prevent bleeding and Asherman's syndrome (Petersen et al. 2016). Presumably, a levonorgestrel intrauterine device could be used to prevent adhesions as well (Römer, Schmidt, and Foth 2000). For ethical considerations of hysteroscopy for CSP, please see the discussion under "Hysterotomy" below, in the section for ethical descriptions of hysteroscopic resection.

\section{Hysterotomy}

A gynecologist can approach surgical resection of a CSP through an open, laparoscopic, or transvaginal approach. The approach and the factual procedure vary widely: an incision in the myometrium is made, and POC are removed either whole or in pieces, with cold instruments (e.g., forceps or curettes), electrocautery, or suction curettage. This can be performed under transabdominal or transrectal ultrasound guidance when a minimally invasive approach is used, or under transvaginal ultrasound if a laparoscopist does not use a uterine manipulator. This can be combined with other interventions to decrease bleeding, such as Bakri balloon placement or UAE (Kanat-Pektas et al. 2016).

One review found that 48.3 percent of such cases are completed laparoscopically, 44.8 percent of cases are completed open, and 6.9 percent of cases 
are completed transvaginally. Surgical resection by any approach succeeds in 92 percent of cases, despite the fact that published cases of hysterotomy have disproportionately greater maternal age, gravidity, parity, and level of $\beta$-hCG than cases of other approaches (Kanat-Pektas et al. 2016). Secondary treatment with $\mathrm{D} \& \mathrm{C}$, systemic methotrexate, UAE, and hysteroscopy is required in 50 percent, 14.3 percent, 7.1 percent, and 7.1 perent of cases, respectively. Hysterectomy is required in 1.7 percent of cases. The transvaginal approach has a low complication rate ( 0.9 percent $)$ in the hands of experienced vaginal surgeons, and no such cases in the literature required retreatment, but statistically significant differences between approaches have not been reported (Petersen et al. 2016). The consensus of medical experts is that a surgeon should use the approach that she or he is most comfortable with considering the appearance of the CSP on ultrasound, her or his expertise, and available equipment and staff.

Considering the ethics of all surgical treatments together (hysteroscopic, laparoscopic, transvaginal, and abdominal) is helpful. It is useful to divide all of these techniques into "gestational excisions" and "scar excisions." These are not obstetrical or gynecological terms. These are words introduced in the present study for the purpose of establishing a distinction among methods of surgical treatment for CSP. "Gestational excision" means the resection of POC only, analogous to salpingostomy (see Figure 4F). Most hysteroscopic and surgical treatment of CSP fall under this category. Unfortunately, most of these involve dismemberment, much like a D\&C. If a living embryo is dismembered, these procedures are direct abortions and are not acceptable. If they do not involve dismemberment, they cannot be automatically dismissed as direct abortions and the complex discussion of indirect abortion ensues. Of course, if embryonic demise is documented, dismemberment is not a concern.

"Scar excision" involves removal of the gestational sac with the surrounding scar en bloc. Resection of the entire scar, including the pregnancy, is different from gestational excision, although it may look similar intraoperatively (see Figure 4D). As mentioned above in discussion of IP, resection of the entire implantation site with a live pregnancy in situ is permissible according to the principle of double effect: the result is clearly an indirect abortion, which is not the expressly desired effect. The preservation of the mother's life is proportional to the unintended loss of the embryo's life. Scar excision is more technically difficult and may lead to more bleeding; raising the risk of vascular, bladder, cervical, and nerve injury; and possibly (depending on the size of the hysterotomy and the comfort of the surgeon and the obstetrician caring for the next pregnancy) making future vaginal delivery unsafe. This technique is not well described and merits careful counseling and consultation with ethics committees and experienced colleagues.

\section{Scar Revision (Pregnancy Salvage)}

Pregnancy salvage is not advised as a treatment for type II CSP, and the first known case is described above. As above, the patient is counseled that removal of the CSP is recommended and pregnancy salvage is experimental. Patients should also be counseled that they are at high risk of abnormal placentation (placenta accreta and placenta previa) as well as placental insufficiency and intrauterine growth restriction. Oversewing the thinned myometrium overlying the gestational sac can be performed via an open or laparoscopic approach. Transfer to a tertiary care center is advised if this is considered, and a low threshold to abandon the surgery should be maintained throughout any pregnancy salvage.

This is the only active management option that allows continuation of a live pregnancy. It should be considered that other management options can leave the woman with intact fertility, while scar revision of a type II CSP will likely lead to hysterectomy and may lead to death. Further cases should be published so that the safety of this method can be scrutinized.

\section{Hysterectomy}

Hysterectomy is a measure of failure of the chosen treatment for CSP and is not advocated as a primary therapy, although the option of elective hysterectomy is extended by medical experts.

Hysterectomy would clearly involve an indirect abortion and again appears as an ethically safe haven. However, as in IP, hysterectomy in CSP should not be performed electively, to avoid removing the good of fertility unnecessarily. Because there are less radical treatments available, hysterectomy should be reserved as a rescue operation unless no other avenue is available with moral certitude. In these cases, documentation should reflect the medical reasons for performing hysterectomy. 
Table I. Techniques Described with Summary of Moral Status.

\begin{tabular}{|c|c|c|}
\hline Technique & Description & Summary \\
\hline $\begin{array}{l}\text { Expectant } \\
\text { management }\end{array}$ & $\begin{array}{l}\text { Awaiting embryonic or fetal death, or } \\
\text { development of viable pregnancy }\end{array}$ & Questionable, licit in some cases \\
\hline $\begin{array}{l}\text { Systemic } \\
\text { methotrexate }\end{array}$ & $\begin{array}{l}\text { Antimetabolite interferes with DNA } \\
\text { synthesis, prohibiting placental growth and } \\
\text { also fetal growth }\end{array}$ & Questionable, likely illicit \\
\hline $\begin{array}{l}\text { Intragestational } \\
\text { methotrexate }\end{array}$ & $\begin{array}{l}\text { Antimetabolite administered directly into the } \\
\text { amniotic cavity }\end{array}$ & Questionable, likely illicit \\
\hline $\begin{array}{l}\text { Intragestational } \\
\mathrm{KCl}\end{array}$ & $\begin{array}{l}\text { Cardiotoxin injected into fetus or amniotic } \\
\text { cavity leading to fetal death }\end{array}$ & Illicit \\
\hline $\begin{array}{l}\text { Double-balloon } \\
\text { catheter }\end{array}$ & $\begin{array}{l}\text { Compression of fetal body and placenta } \\
\text { leading to cessation of blood flow and fetal } \\
\text { death }\end{array}$ & Illicit \\
\hline $\begin{array}{l}\text { Uterine artery } \\
\text { embolization }\end{array}$ & $\begin{array}{l}\text { Occlusion of one or both uterine arteries to } \\
\text { cut off blood supply to fetus or to decrease } \\
\text { hemorrhage }\end{array}$ & $\begin{array}{l}\text { Illicit when used to cause fetal death; licit } \\
\text { when used to prevent hemorrhage }\end{array}$ \\
\hline $\begin{array}{l}\text { Dilation and } \\
\text { curettage }\end{array}$ & $\begin{array}{l}\text { Removal of products of conception in pieces } \\
\text { through the cervix }\end{array}$ & $\begin{array}{l}\text { Illicit when performed on a living fetus, licit } \\
\text { otherwise }\end{array}$ \\
\hline Cornuostomy & $\begin{array}{l}\text { Perforation of the uterine cornu and removal } \\
\text { of products of conception whole or in } \\
\text { pieces }\end{array}$ & $\begin{array}{l}\text { Questionable when performed on a living } \\
\text { fetus, licit otherwise }\end{array}$ \\
\hline Salpingostomy & $\begin{array}{l}\text { Incision of the fallopian tube and removal of } \\
\text { products of conception whole or in pieces }\end{array}$ & $\begin{array}{l}\text { Questionable when performed on a living } \\
\text { fetus, licit otherwise }\end{array}$ \\
\hline $\begin{array}{l}\text { Cornual wedge } \\
\text { resection }\end{array}$ & $\begin{array}{l}\text { Resection of an interstitial pregnancy and the } \\
\text { part of the uterus enclosing it }\end{array}$ & Licit \\
\hline $\begin{array}{l}\text { Gestational } \\
\text { excision }\end{array}$ & $\begin{array}{l}\text { Removal of products of conception from a } \\
\text { cesarean scar, whole or in pieces }\end{array}$ & $\begin{array}{l}\text { Illicit when performed on a living fetus, } \\
\text { questionable otherwise }\end{array}$ \\
\hline Scar excision & $\begin{array}{l}\text { Resection of a cesarean scar pregnancy and } \\
\text { the part of the uterus enclosing it }\end{array}$ & Licit \\
\hline $\begin{array}{l}\text { Scar revision } \\
\text { (pregnancy } \\
\text { salvage) }\end{array}$ & $\begin{array}{l}\text { Reinforcement of the cesarean scar in order } \\
\text { to promote viable pregnancy }\end{array}$ & Questionable \\
\hline Hysterectomy & $\begin{array}{l}\text { Resection of the entire uterus including the } \\
\text { ectopic pregnancy }\end{array}$ & $\begin{array}{l}\text { Licit, but generally to be avoided in order to } \\
\text { preserve fertility, unless no other licit } \\
\text { option is available }\end{array}$ \\
\hline
\end{tabular}

Note: DNA, deoxyribonucleic acid.

Table 2. Cases Described with Summary of Moral Status.

\begin{tabular}{|c|c|c|}
\hline Case & Technique Used & Summary \\
\hline $\begin{array}{l}\text { Case I: Uncomplicated surgical } \\
\text { management of interstitial } \\
\text { pregnancy }\end{array}$ & Ultrasound-guided suction dilation and curettage & Illicit \\
\hline $\begin{array}{l}\text { Case 2: Surgical management of } \\
\text { ruptured interstitial } \\
\text { pregnancy }\end{array}$ & $\begin{array}{l}\text { Diagnostic laparoscopy, conversion to laparotomy, } \\
\text { supracervical hysterectomy, and right } \\
\text { salpingectomy }\end{array}$ & Licit \\
\hline $\begin{array}{l}\text { Case 3: Medical and surgical } \\
\text { management of cesarean scar } \\
\text { pregnancy }\end{array}$ & $\begin{array}{l}\text { Multidose regimen of systemic methotrexate, } \\
\text { suction dilation, and curettage after cardiac } \\
\text { motion disappeared }\end{array}$ & $\begin{array}{l}\text { Licit if systemic } \\
\text { methotrexate is } \\
\text { morally acceptable }\end{array}$ \\
\hline $\begin{array}{l}\text { Case 4: Surgical salvage of } \\
\text { cesarean scar pregnancy }\end{array}$ & $\begin{array}{l}\text { Transvaginal ultrasound-guided laparoscopic } \\
\text { imbrication of the lower uterine segment }\end{array}$ & Licit \\
\hline
\end{tabular}




\section{Conclusions}

Although extrauterine tubal pregnancies make up 90-93 percent of ectopic pregnancies, there are medications and techniques used for other ectopic pregnancies that have not been formally addressed by Catholic physicians or bioethicists. Two relatively common types of ectopic pregnancy are presented: interstitial pregnancy, located in the intrauterine portion of the fallopian tube, and cesarean scar pregnancy, located in a healed hysterotomy from a prior cesarean delivery. Treatment options proposed by medical literature were reviewed, including expectant management, systemic methotrexate, intragestational methotrexate, intragestational potassium chloride, UAE, D\&C, vasopressin use, cornuostomy, cornual wedge resection, salpingostomy, "gestational excision" (here meaning excision of POC), "scar excision" (here meaning excision of the uterine tissue surrounding a CSP with pregnancy in situ), scar revision or pregnancy salvage, and hysterectomy.

The options for live IPs and CSPs which are clearly morally safe are cornual wedge resection and scar excision because they both clearly constitute indirect abortions, analogous to salpingectomy in extrauterine tubal pregnancies. Less clearly licit are cornuostomies, salpingostomies (for IPs), and gestational excisions because they carry the same concerns as salpingostomy, including the concern for dismemberment of a living human person. Also unclear and problematic are systemic and intragestational methotrexate. Certainly illicit are D\&Cs on live embryos or fetuses, any other technique which dismembers an embryo or fetus, use of the doubleballoon catheter for embryocide, and use of $\mathrm{KCl}$. UAE and hysterectomy can be used as rescue procedures; UAE may be a serious reason for postponing future pregnancies, and hysterectomy in this case constitutes secondary sterilization. Expectant management should be offered for very few patients with IP and CSP. See Table 1 for a summary of the morality of these techniques.

Notably, the first case was managed with D\&C, although fetal heart tones had been documented and no absent heart tones were noted prior to the procedure. According to this ethical analysis, this management decision should not be repeated. The second case documented use of hysterectomy as a rescue procedure, incurring secondary sterilization as an accidental effect of a lifesaving operation. The third case employed methotrexate, used with moral certitude by the prescribing team, and only carried out dismembering D\&C after documentation of absence of fetal heart tones. Ethical considerations of the fourth case include weighing the likelihood of maternal death and loss of fertility with the desire for the child. Since the human life that the patient chose to carry is priceless and eternal, the decision of the patient cannot be scrutinized. The decision of the treating team cannot be condemned as long as informed consent was given regarding the risk of sterility and death (see Table 2 for a summary of the cases).

\section{Acknowledgments}

The author wishes to thank Emanuel Vlastos, MD, Eugen Campian, MD, and Andrew Steele, MD, for allowing the study and publication of their patients' cases.

\section{Declaration of Conflicting Interests}

The author(s) declared no potential conflicts of interest with respect to the research, authorship, and/or publication of this article.

\section{Funding}

The author(s) received no financial support for the research, authorship, and/or publication of this article.

\section{Notes}

1. In developmental biology, a human organism is called an "embryo" through ten weeks and six days gestational age (eight weeks six days conceptional age) and a "fetus" from eleven gestational weeks (or nine conceptional weeks) onward, although development is a continuum (see, for reference, Langman's Medical Embryology, cited below).

2. In obstetric literature, the term "cornual" pregnancy is sometimes incorrectly used to describe these pregnancies. A "cornual" pregnancy is that resulting in one horn of a bicornuate uterus. For the sake of further clarification, an "angular" pregnancy is an intrauterine, viable pregnancy implanted adjacent to the tubal ostium, and an "isthmic" pregnancy is a variety of tubal pregnancy in the portion of the tube closest to the uterine corpus but still outside it.

3. Many prolife physicians oppose the use of this term as depersonalizing. However, it is useful for its succinctness and its vagueness can actually be used to protect potential human life. Products of conception is a short way to refer to a living or deceased embryo or fetus with or without the gestational membranes and amniotic fluid, or any molar or anembryonic result of fertilization, which are or are not persons but should be treated as persons until death is certain. 


\section{References}

Arleo, Elizabeth Kagan, and Ersilia M. Defilippis. 2014. "Cornual, Interstitial, and Angular Pregnancies: Clarifying the Terms and a Review of the Literature." Clinical Imaging 38, no. 6: 763-70.

Ashley, Benedict M., and Kevin D. O’Rourke. 2002. Ethics of Health Care: An Introductory Textbook. Washington, DC: Georgetown UP.

Aquinas, Thomas. 1920. The "Summa Theologica" of St. Thomas Aquinas. London, UK: Burns Oates \& Washbourne, Web. May 6, 2017.

Bernstein, Ira M. 2002. "Uterine Artery Hemodynamic Adaptations through the Menstrual Cycle into Early Pregnancy." Obstetrics \& Gynecology 99, no. 4: 620-24.

Betrán, Ana Pilar, Jianfeng Ye, Anne-Beth Moller, Jun Zhang, A. MetinGülmezoglu, and Maria Regina Torloni. 2016. "The Increasing Trend in Caesarean Section Rates: Global, Regional and National Estimates: 19902014." PLoS One 11, no. 2: e0148343.

Bouyer, Jean. 2002. "Sites of Ectopic Pregnancy: A 10 Year Population-based Study of 1800 Cases." Human Reproduction 17, no. 12: 3224-30.

Campion, Edward W., Peter M. Doubilet, Carol B. Benson, Tom Bourne, and Michael Blaivas. 2013. "Diagnostic Criteria for Nonviable Pregnancy Early in the First Trimester." New England Journal of Medicine 369, no. 15: 1443-51.

Chatterjee, Jayanta, Asma Abdullah, Fatai A. Sanusi, Laurie Irvine, and David Griffin. 2009. "A Rare Sequel following Cornual Ectopic Pregnancy: A Case Report." Case Reports 2009, no. February: 1614.

Chen, Q., S. S. Schreiber, and Roberta D. Brinton. 2000. "Vasopressin and Oxytocin Receptor MRNA Expression during Rat Telencephalon Development." Neuropeptides 34, nos. 3-4: 173-80.

Chetty, Maya, and Janine Elson. 2009. "Treating Non-tubal Ectopic Pregnancy.” Best Practice \& Research Clinical Obstetrics \& Gynaecology 23, no. 4: 529-38.

Čikoš, Štefan, Sona Czikková, Peter Chrenek, Alexander V. Makarevich, Jan Burkuš, Žofia Janštová, Dusan Fabian, and Juraj Koppel. 2013. "Expression of Adrenergic Receptors in Bovine and Rabbit Oocytes and Preimplantation Embryos." Reproduction in Domestic Animals 49, no. 1: 92-100.

Collins, Kelly, and Alka Kothari. 2015 "Catastrophic Consequences of a Caesarean Scar Pregnancy Missed on Ultrasound." Australasian Journal of Ultrasound Medicine 18, no. 4: 150-156.

Dähnert, Wolfgang. 2007. Radiology Review Manual. Philadelphia, PA: Wolters Kluwer/Lippincott Williams \& Wilkins.

De Blois, Jean, Patrick Norris, and Kevin D. O'Rourke. 1994. A Primer for Health Care Ethics: Essays for a Pluralistic Society. Washington, DC: Georgetown University Press.

DeGoede, Maria. 2014. “An Argument against the Use of Methotrexate in Ectopic Pregnancies." The National Catholic Bioethics Quarterly 14, no. 4: 625-35.
Foster, Angel M., Amanda Dennis, and Fiona Smith. 2011. "Do Religious Restrictions Influence Ectopic Pregnancy Management? A National Qualitative Study." Women's Health Issues 21, no. 2: 104-09.

Fylstra, Donald L. 2002. "Ectopic Pregnancy within a Cesarean Scar: A Review." Obstetrical \& Gynecological Survey 57, no. 8: 537-43.

Grobman, W. A., and M. P. Milad. 1998. "Conservative Laparoscopic Management of a Large Cornual Ectopic Pregnancy." Human Reproduction 13, no. 7: 2002-04.

Guevin, Benedict M. 2007. "The Use of Methotrexate or Salpingostomy in the Treatment of Tubal Ectopic Pregnancies." The National Catholic Bioethics Quarterly 7, no. 2: 249-56.

Gury, Jean Pierre, and Antonio Ballerini. 1882. Compendium theologiae moralis; Ioannis Petri Gury ab Auctore recognitum et Antonii Ballerini adnotatibus locupletatum. Romae: Ex Typographia Polyglotta.

Hager, Samuel E. 2016. "Against Salpingostomy as a Treatment for Ectopic Pregnancy." The National Catholic Bioethics Quarterly 16, no. 1: 39-48.

Hehenkamp, W. J., N. A. Volkers, F. J. Broekmans, F. H. De Jong, A. P. Themmen, E. Birnie, J. A. Reekers, and W. M. Ankum. 2007. "Loss of Ovarian Reserve after Uterine Artery Embolization: A Randomized Comparison with Hysterectomy." Human Reproduction 22, no. 7: 1996-2005.

Jermy, Karen, James Thomas, Alex Doo, and Tom Bourne. 2004. "The Conservative Management of Interstitial Pregnancy." BJOG: An International Journal of Obstetrics \& Gynaecology 111, no. 11: 1283-88.

Jones, Howard W., and John A. Rock. 2015. Te Linde's Operative Gynecology. Philadelphia, PA: Lippincott Williams \& Wilkins.

Jurkovic, D., K. Hillaby, B. Woelfer, A. Lawrence, R. Salim, and C. J. Elson. 2003. "First-Trimester Diagnosis and Management of Pregnancies Implanted into the Lower Uterine Segment Cesarean Section Scar." Obstetrical \& Gynecological Survey 58, no. 9: 567-69.

Kaczor, Christopher. 2009. "The Ethics of Ectopic Pregnancy: A Critical Reconsideration of Salpingostomy and Methotrexate." The Linacre Quarterly 76, no. 3: 265-82.

Kanat-Pektas, Mine, Serkan Bodur, Ozgur Dundar, and Vuslat Lale Bakir. 2016. "Systematic Review: What Is the Best First-Line Approach for Cesarean Section Ectopic Pregnancy?" Taiwanese Journal of Obstetrics and Gynecology 55, no. 2: 263-69.

Lau, Susie, and Togas Tulandi. 1999. "Conservative Medical and Surgical Management of Interstitial Ectopic Pregnancy." Fertility and Sterility 72, no. 2: 207-15.

Mangan, Joseph T. 1949. "An Historical Analysis of the Principle of Double Effect.” Theological Studies 10, no. 1: 41-61.

Maruthini, Deivanayagam, and Vinay Sharma. 2013. “A Case of Live Birth after Uterine Reconstruction for Recurrent Cornual Ectopic Pregnancy following IVF Treatment." Case Reports in Obstetrics and Gynecology 2013: 1-6. 
May, William E. 1994. "The Management of Ectopic Pregnancies: A Moral Analysis." In The Fetal Tissue Issue: Medical and Ethical Aspects, edited by Peter J. Cataldo, and Albert S. Moraczewski, 121-141. Braintree, MA: Pope John Center.

May, William E. 2008. Catholic Bioethics and the Gift of Human Life. Huntington, IN: Our Sunday Visitor.

Moawad, Nash S., Sangeeta T. Mahajan, Michelle H. Moniz, Sarah E. Taylor, and William W. Hurd. 2010. "Current Diagnosis and Treatment of Interstitial Pregnancy." American Journal of Obstetrics and Gynecology 202, no. 1: 15-29.

Moawad, N., S. Dayaratna, and S. Mahajan. 2008. "Minicornual Excision: A Novel Stepwise Laparoscopic Technique for the Treatment of Cornual Pregnancy." Journal of Minimally Invasive Gynecology 15, no. 6: $64 \mathrm{~S}$.

Moon, Hwa Sook, Young Joo Choi, Yang Hee Park, and Sang Gap Kim. 2000. "New Simple Endoscopic Operations for Interstitial Pregnancies." American Journal of Obstetrics and Gynecology 182, no. 1: 114-21.

$\mathrm{Ng}$, Selma, Suttha Hamontri, Irene Chua, Bernard Chern, and Anthony Siow. 2009. "Laparoscopic Management of 53 Cases of Cornual Ectopic Pregnancy." Fertility and Sterility 92, no. 2: 448-52.

Nirgianakis, Konstantinos, Andrea Papadia, Giovanni Grandi, Brett Mckinnon, Daniele Bolla, and Michael D. Mueller. 2016. "Laparoscopic Management of Ectopic Pregnancies: A Comparison between Interstitial and "More Distal" Tubal Pregnancies." Archives of Gynecology and Obstetrics 295, no. 1: 95-101.

Paul, VI. 1993. Humanae Vitae, of Human Life: An Encyclical Letter, with commentary by Janet E. Smith, and Thomas W. Hilgers. Omaha, NE: Pope Paul VI Institute.

Petersen, Kathrine Birch, Elise Hoffmann, Christian Rifbjerg Larsen, and Henriette Svarre Nielsen. 2016. "Cesarean Scar Pregnancy: A Systematic Review of Treatment Studies." Fertility and Sterility 105, no. 4: 958-67.

Pron, Gaylene, Eva Mocarski, John Bennett, George Vilos, Andrew Common, and Leslie Vanderburgh. 2005. "Pregnancy after Uterine Artery Embolization for Leiomyomata." Obstetrics \& Gynecology 105, no. 1: 67-76.

Ravina, Jacques Henri, Nicole Ciraru Vigneron, Armand Aymard, Olivier Le Dref, and Jean Jacques Merland. 2000. "Pregnancy after Embolization of Uterine Myoma: Report of 12 Cases." Fertility and Sterility 73, no. 6: 1241-43.

Rotas, Michael A., Shoshana Haberman, and Michael Levgur. 2006. "Cesarean Scar Ectopic Pregnancies." Obstetrics \& Gynecology 107, no. 6: 1373-81.

Römer, T., T. Schmidt, and D. Foth. 2000. "Pre- and Postoperative Hormonal Treatment in Patients with
Hysteroscopic Surgery." Contributions to Gynecology and Obstetrics Hysteroscopy 20: 1-12.

Sadler, Thomas W., Susan L. Sadler-Redmond, Kathy Tosney, Jan Byrne, and Hytham Imseis. 2015. Langman's Medical Embryology. Philadelphia, PA: Wolters Kluwer.

Samal, Sunilkumar, and Setu Rathod. 2015. “A True Cornual Pregnancy with Placenta Percreta Resulting in a Viable Fetus." International Journal of Applied and Basic Medical Research 5, no. 3: 203.

Shen, Licong, Fu Jing, Wei Huang, Huili Zhu, Qiushi Wang, Shiyuan Yang, and Wu Taixiang. 2014. "Interventions for Non-tubal Ectopic Pregnancy." Cochrane Database of Systematic Reviews, no. 7: 1-16.

Stika, Catherine S. 2012. "Methotrexate." Clinical Obstetrics and Gynecology 55, no. 2: 433-39.

Tang, Amy, David Baartz, and Soo KeatKhoo. 2006. “A Medical Management of Interstitial Ectopic Pregnancy: A 5-year Clinical Study." The Australian and New Zealand Journal of Obstetrics and Gynaecology 46, no. 2: 107-11.

Timor-Tritsch, Ilan E., and Ana Monteagudo. 2012. "Unforeseen Consequences of the Increasing Rate of Cesarean Deliveries: Early Placenta Accreta and Cesarean Scar Pregnancy. A Review." American Journal of Obstetrics and Gynecology 207, no. 1: 14-29.

Timor-Tritsch, Ilan E., Ana Monteagudo, Terri-Ann Bennett, Christine Foley, Joanne Ramos, and Andrea KaelinAgten. 2016. "A New Minimally Invasive Treatment for Cesarean Scar Pregnancy and Cervical Pregnancy.” Obstetrical \& Gynecological Survey 72, no. 1: 21-22.

Timor-Tritsch, I. E., A. Monteagudo, G. Cali, A. Vintzileos, R. Viscarello, A. Al-Khan, S. Zamudio, P. Mayberry, M. M. Cordoba, and P. Dar. 2014. "Cesarean Scar Pregnancy Is a Precursor of Morbidly Adherent Placenta." Ultrasound in Obstetrics \& Gynecology 44 no. 3: 346-53.

Tulandi, T., G. Vilos, and V. Gomel. 1995. "Laparoscopic Treatment of Interstitial Pregnancy." Obstetrics \& Gynecology 85, no. 3: 465-67.

Wye, Deborah, Robert Magotti, Dheya Al-Mashat, Ronald Benzie, and George Condous. 2014. "Sonographic Diagnosis of Spontaneous Uterine Rupture at the Site of Cornual Wedge Resection Scar-A Case Report." Australasian Journal of Ultrasound in Medicine 17, no. 1: 45-48.

\section{Biographical Note}

Cara Buskmiller, MD, is a consecrated virgin in the Archdiocese of St. Louis. She received a bachelor's degree in liberal arts from Thomas Aquinas College and is currently a third-year resident in obstetrics and gynecology at St. Louis University. 